\title{
Oficinas pegagógicas: construindo estratégias para a atuação docente no ensino de alunos autistas - Relato de experiência
}

\author{
Educational workshops: building teaching strategies for \\ education of students with autism - Experience report
}

Paula Raimunda Araújo Teixeira', Maicon de Araujo Nogueira², Antônia Margareth Moita Sá2, Lúcia Menezes de Medeiros², Ivonete Vieira Pereira Peixoto²

'Universidade Federal do Pará, Belém (PA), Brasil.

${ }^{2}$ Universidade do Estado do Pará, Belém (PA), Brasil

\section{RESUMO}

Contextualização: Este artigo consiste de um relato de experiência da execução de oficinas pedagógicas no estágio de monitoria em um Centro de Atendimento Psicológico Infantil (CAPSi), localizado no município de Ananindeua, Pará, no período de setembro a novembro de 2015, delineado a partir de métodos descritivos, observacionais e participativos. Objetivou-se com o presente estudo descrever as estratégias pedagógicas e experiências formativas desenvolvidas durante o estágio de monitoria no acompanhamento de crianças autistas, tendo como foco de atuação, alcançar seus níveis de desenvolvimento potencial, utilizando como base para reflexões, a teoria sócio histórica de Vygotsky, a qual afirma que o desenvolvimento humano se dá por meio das relações sociais que o indivíduo estabelece no decorrer de sua vida, ou seja, que o processo de ensino-aprendizagem também se desenvolve por meio das interações que vão se desenrolando no decorrer da vida. Descrição da experiência: Ressaltamos alguns casos de evolução em relação à interação social, aspecto mais comprometido em pessoas autistas, enfatizando a importância da intervenção para o desenvolvimento pleno destas pessoas desde a infância. Considerações finais: O aprendizado e o resultado da aplicação destas metodologias são registros importantes no quotidiano da prática dos profissionais de saúde, por desenvolver nestes um olhar mais aguçado em torno das pessoas com necessidades especiais, valorizando suas potencialidades dentro e fora do ambiente escolar com vista a promover a emancipação humana, que é o verdadeiro exercício da cidadania.

PALAVRAS-ChAVE: Transtorno autístico. Docentes. Ensino de recuperação.

\section{CORRESPONDÊNCIA}

Maicon de Araujo Nogueira

Universidade do Estado do Pará

Psg Jhon Engelhard, 285, Pratinha II,

Psg Jhon Engelhard, 285, Pratinha

Tel.: (91) 3258-3569/

Cel.: (91) 98043- 6368

enfnogueira@globomail.com

\section{FONTE DE FINANCIAMENTO}

Estudo autofinanciado.

\section{CONFLITO DE INTERESSE}

Os autores declararam não

haver conflitos de interesse.

O estudo foi realizado no Centro de Atendimento Psicológico Infantil (CAPSi), localizado no município de Ananindeua (PA), Brasil.

\section{ABSTRACT}

Contextualization: This article is an experience report of the educational workshops operation during a monitoring internship at a Psychological Child Care Center (Centro de Atendimento Psicológico Infantil - CAPSi), situated in the city of Ananindeua, Para, from September to November 2015, outlined from descriptive, observational and participatory methods. The present study aims to describe the pedagogical strategies and formative experiences developed during the monitoring internship in the supervision of autistic children. The main focus was the achievement of their potential development levels, using Vygotsky's social-historical theory as reflective basis, which states human development is implemented through the social contacts an individual sets out throughout his/her life, i.e., the teaching-learning process is also developed through interactions that will happen during life. Description of the experience: It is necessary to emphasize some cases of progress in terms of social interaction, most affected aspect in autistic people, underlining the importance of the intervention for the full development of those people since childhood. Final considerations: The learning and the result of the over mentioned methodologies are important records in the everyday practice of health professionals, to develop a sharper glance at people with special needs, promoting their potential inside and outside of school environment, in order to foster human empowerment that is the true exercise of citizenship. KEYWORDS: Autistic disorder. Teachers. Remedial education. 


\section{Contextualização}

O presente estudo relata as experiências de monitoria no acompanhamento de crianças autistas durante o processo de ensino-aprendizagem, envolvendo discentes e docentes, durante oficinas ministradas no Centro de Atendimento Psicológico Infantil (CAPSi/Ananindeua-Pa). No cenário atual da educação, é recorrente observarmos pessoas com deficiência e seus familiares relatarem sobre a importância da escola, seus gestores e professores promoverem a verdadeira inclusão nesses ambientes.

Quanto a essa discussão sobre a organização da escola, o atendimento adequado a ser oferecido a Pessoa com Deficiência (PcD), principalmente relacionado a capacitação dos professores que desenvolvem ou irão desenvolver atividades pedagógicas, nas salas de aulas comuns, para incluir todos os alunos, o artigo 27 da Lei no 13.146/15 orienta e assegura que: "A educação constitui direito da pessoa com deficiência, assegurados sistema educacional inclusivo em todos os níveis de aprendizado ao longo de toda vida", dessa forma buscando a alcançar o máximo desenvolvimento possível, tanto de seus talentos e habilidades físicas, quanto sensoriais, intelectuais e sociais, respeitando suas características, interesses e necessidades de aprendizagem ${ }^{1}$.

As legislações construídas historicamente no país têm corroborado no sentido de produzir grandes transformações no contexto educacional brasileiro ${ }^{2,3}$. Esta situação pode ser observada nos dados do Censo Escolar em relação à educação especial, demonstrando uma evolução no número de matrículas, que passou de $337.326 \mathrm{em}$ 1998 para 900.000 em 2014, expressando um crescimento de $300 \%$ no número de alunos matriculados no ensino regular. Em relação ao ingresso em classes comuns, verificou-se em 1998 que 13\% dos alunos matriculados estavam frequentando as classes comuns no ensino regular, e em 2014, os dados demonstraram que esta porcentagem passou para $79 \%^{4}$.

A implantação da Lei Berenice Piana (Lei no 12.764/12), que institui o direito das pessoas com Transtorno do Espectro Autista é um dos primeiros passos para a inserção delas no ambiente escolar. Assegurando no Artigo $2^{\circ}$, o incentivo à formação e à capacitação de profissionais especializados no atendimento à pessoa com transtorno do espectro autista, tornando-a obrigatória e enfatizando a capacitação dos profissionais ${ }^{5,6}$.

De acordo com Ministério da Educação “[...] a formação e a capacitação docente impõem-se como meta principal a ser alcançada na concretização do sistema educacional que inclua a todos, verdadeiramente"

O Ministério da Educação comparou dados do Censo Escolar de 2003 e 2013, e apontou um crescimento de $177 \%$ na formação de professores em educação especial. Em 2013 o censo contabilizou 93.371 educadores, contrapondo os dados de 2003, que eram apenas de 33.691 professores formados ${ }^{4}$.

Os dados supracitados salientam uma reflexão; existe um aumento real no quantitativo de alunos nas escolas regulares, ou seja, eles têm tido acesso às escolas, o que é positivo, entretanto surgem alguns questionamentos: como está a qualidade do ensino ofertado estes alunos? Como os professores estão sendo capacitados? As escolas estão realmente preparadas? Estes questionamentos não podem ser quantificados, mas sim observados e analisados, para assim conhecermos sua evolução dentro da sociedade.

Justifica-se a escolha desse tema, como forma de contribuição aos estudos sobre inclusão de crianças autistas na rede de educação da Região Norte, compartilhando a experiência de monitoria, na qual, apresentamos e descrevemos algumas metodologias intervencionistas e orientações em relação ao acolhimento de pessoas autistas, mais especificamente crianças. Dessa forma, objetivamos com o presente estudo descrever as estratégias pedagógicas e experiências formativas desenvolvidas durante o estágio de monitoria no acompanhamento de crianças autistas, assim como propor algumas orientações para o relacionamento com autistas e descrever os recursos pedagógicos utilizados pelos profissionais do Centro de Atendimento Psicológico Infantil (CAPSi) na interação com crianças autistas. 


\section{Descrição da experiência}

Trata-se de um relato de experiência que descreve aspectos vivenciados pelos autores, na oportunidade de um estágio de monitoria no Centro de Atendimento Psicológico Infantil (CAPSi), localizado no município de Ananindeua-Pará, no período de setembro a novembro de 2015, após a prévia autorização da coordenação e direção. Trata-se de um olhar qualitativo, que abordou a problemática delineada a partir de métodos descritivos, observacionais e participativos.

O Centro atende gratuitamente crianças com deficiência intelectual, paralisia cerebral, Transtorno Global do Desenvolvimento (TGD), hiperatividade e déficit de atenção. Promovendo o diagnóstico e o tratamento continuado, constituído por equipe multidisciplinar, visando atender as crianças em todas as suas necessidades, tanto físicas quanto psicológicas, e promover seu desenvolvimento pleno.

O relato de experiência é uma ferramenta da pesquisa descritiva que apresenta uma reflexão sobre uma ação ou um conjunto de ações que abordam uma situação vivenciada no âmbito profissional de interesse da comunidade científica8 .

O projeto desta pesquisa não foi submetido ao Comitê de Ética em Pesquisa por se tratar de relato de experiência dos autores, com anuência do local onde ocorreu o estágio curricular não obrigatório e garantias de confidencialidade dos dados. Utilizou-se das seguintes técnicas de coleta de dados: diário de campo, observação estruturada (pesquisador participante), consulta à ficha de atendimento clínico, participação nas atividades (oficinas pedagógicas). Não foram utilizados dados pessoais, apenas aqueles de interesse para o estudo, porém sem fazer qualquer menção a dados que pudessem identificar os participantes da pesquisa.

\section{Resultados e impactos}

\section{As etapas da monitoria}

Durante a monitoria, acompanharam-se as atividades da psicóloga e da pedagoga responsáveis pela elaboração e aplicação das oficinas. Chegando ao local, houve a recepção realizada pela psicóloga, o que favoreceu a familiarização com o ambiente e possibilitou o conhecimento acerca da dinâmica das atividades, os horários disponíveis e objetivos de aprendizagem propostos.

As oficinas eram ofertadas três vezes por semana, segunda, terça e quarta das $09 \mathrm{~h} 00 \mathrm{~min}$ às $12 \mathrm{~h} 00 \mathrm{~min}$. A monitoria foi dividida em três momentos, que serão descritos a seguir:

Etapa 01: preparação

Neste momento, foram realizadas algumas pesquisas em artigos e literatura pertinente, cujos temas fossem estratégias para incluir crianças e jovens autistas nos diversos níveis de ensino, com o foco principal na educação básica. As pesquisas foram realizadas durante o período de dois meses nas bases de dados SCIELO e LILACS, e após o levantamento realizou-se a leitura deste material, tendo como objetivo o aprofundamento do assunto para subsidiar as ações na monitoria.

Etapa 02: observação

Durante este período apenas eram observadas as ações realizadas pela psicóloga e pela pedagoga, sem interferência. Esta etapa ocorreu durante duas semanas.

Etapa 03: intervenção

Neste período, iniciou-se de fato a participação nas oficinas, aplicando as atividades propostas juntamente com as responsáveis, comunicando-se com as crianças e seus familiares. Este momento pode proporcionar um melhor relacionamento com as crianças, a chance de perceber melhora na comunicação de alguns e aumento na 
interação entre eles. A última etapa foi marcada pela coleta de informações sobre as estratégias. Todas as atividades propostas possuíam um objetivo que eram explicadas aos envolvidos antes do início da oficina e anotados.

\section{Orientações e metodologia}

Os grupos atendidos durante as oficinas eram formados por crianças entre 05 a 10 anos, em sua maioria meninos. Todos pacientes do centro, e com diagnóstico de autismo, variando de graus leves aos mais graves.

As oficinas atendiam em média 15 crianças por dia, devido o número de pessoas disponíveis para ministra-las. As crianças eram separadas por idade em três grupos, em números iguais, atendidos em horários diferentes e pré-determinados. Cada oficina durava uma hora, e em alguns casos, os responsáveis das crianças participavam do momento. Estas medidas objetivavam organizar e evitar a exposição direta a estímulos diversos e intensos, pois tais estímulos poderiam sobrecarregá-las pela saturação de informações, levando-as a apresentar um comportamento desorganizado, devido à dificuldade em comunicar suas necessidades ${ }^{9}$.

A oficina contava com dois momentos, o primeiro era o de acolhimento das crianças. Esta etapa era marcada pela socialização entre eles. O segundo momento era a aplicação das atividades estimulantes, como desenho livre, pintura etc.

Os dois momentos possuíam instrumentos de mediação diferentes, porém com um mesmo objetivo: melhorar a interação das crianças com o meio.

Segundo a abordagem sócio histórica, a aprendizagem e o desenvolvimento são processos intrinsecamente relacionados e atuam por meio de um processo dialético ${ }^{10,11}$.

\section{Primeiro momento}

O primeiro momento consistia principalmente em acolher as crianças, e sinalizar o início das atividades, passos importantes para o relacionamento com autistas, visto que eles são ritualizados, possuem dificuldades para interagir com seus pares e muitas vezes, apresentam dificuldades em mudar de rotina ${ }^{12}$.

Essa etapa objetiva inserir as crianças naquele novo momento, tentando acalma-los ao máximo. Colocávamos músicas infantis, alegres e conhecidas por muitos deles, que os estimulavam a cantar e dançar conosco e com seus pares, ou seja, promovíamos sua interação com o meio, pois a interação é um meio de campo essencial de realidade socialmente compartilhada, fornecendo o contexto intersubjetivo para o processo de simbolização ${ }^{13}$.

\section{Segundo momento}

Após o acolhimento, dávamos início às atividades estimulantes. Cada criança apresentava grau diferente de autismo, e como a oficina era uma continuidade do tratamento, a psicóloga conhecia o perfil dos pacientes e suas necessidades naquele momento, ou seja, cada criança realizava uma atividade específica, elaborada para ela e que iria contemplar alguma de suas necessidades. Tomando como referência a abordagem de Vygotsky11, atuávamos justamente na Zona de Desenvolvimento Proximal (ZDP) das crianças, buscando por meio das atividades, alcançar os níveis de desenvolvimento potencial delas.

Podemos citar como exemplo o caso de uma das crianças que iniciou as oficinas no mesmo período da monitoria, então podemos acompanhar sua evolução com o grupo mais detalhadamente. Ele, incialmente com pouquíssima interação, após três meses, já segurava na mão dos colegas durante as brincadeiras de roda e aceitava o nosso toque.

No caso acima, podemos dizer que no momento inicial, o nível de desenvolvimento real dessa criança era a baixa interação, porém através da mediação (brincadeiras), estávamos alcançando o seu nível de desenvolvimento potencial, ou seja, aumentando 
sua capacidade de interagir com seus pares. Como acreditava Vygotsky ${ }^{11}$, as características individuais e até mesmo suas atitudes individuais estão impregnadas de trocas com o coletivo, portanto, mesmo o que tomamos por mais individual de um ser humano foi construído a partir de sua relação com o indivíduo.

Ao final de todas as oficinas, as crianças eram estimuladas a guardar os brinquedos e/ou objetos com os quais elas tinham brincado durante as atividades, objetivando promover a disciplina e organização sensorial delas dentro e fora daquele ambiente. Essa atitude é importante devido ao fato de crianças autistas responderem bem a sistemas organizados, por isso, o professor ou mediador deve organizar o ambiente para conseguir ensinar os alunos e estes poderem desenvolver as suas competências ${ }^{14}$.

\section{Os recursos}

Durante as oficinas foram utilizados diversos recursos como instrumentos mediadores, e a seguir apresentamos alguns deles e seus objetivos.

Algumas atividades propostas: realização de pinturas e desenhos utilizando tinta guache, lápis de cor e pincel; colagem com papel crepom; musicoterapia, utilizando músicas infantis; utilização de brinquedos educativos como quebra cabeça, lego e jogo da memória para estimular o raciocínio; uso da bola de borracha para estimular a confiança e o equilíbrio; utilização da árvore sensorial com diversas texturas; uso da estratégia do "faz de conta", para estimular a imaginação da criança autista, pois esta percebe com mais facilidade o concreto.

O desenho livre (Figura 1) foi um recurso utilizado para estimular o desenvolvimento motor fino, visto que as crianças autistas possuem dificuldades na movimentação das mãos, influenciando também na sua escrita. Elas utilizavam o quadro magnético e caneta piloto ou folhas de papel A4 na cor branca e lápis de cor para fazer seus desenhos.

A atividade denominada "Faz de conta" (Figura 2) objetivava estimular a criatividade das crianças, considerando que pessoas com autismo possuem dificuldade com linguagem não literal. Estimulávamos assim sua imaginação, inventando histórias e simulando situações cotidianas (vinhetas), como cozinhar, ir ao salão de beleza, entre outras.

Um dos diálogos entre uma das crianças e eu durante a atividade:

"- O que é isso? É um hambúrguer?"

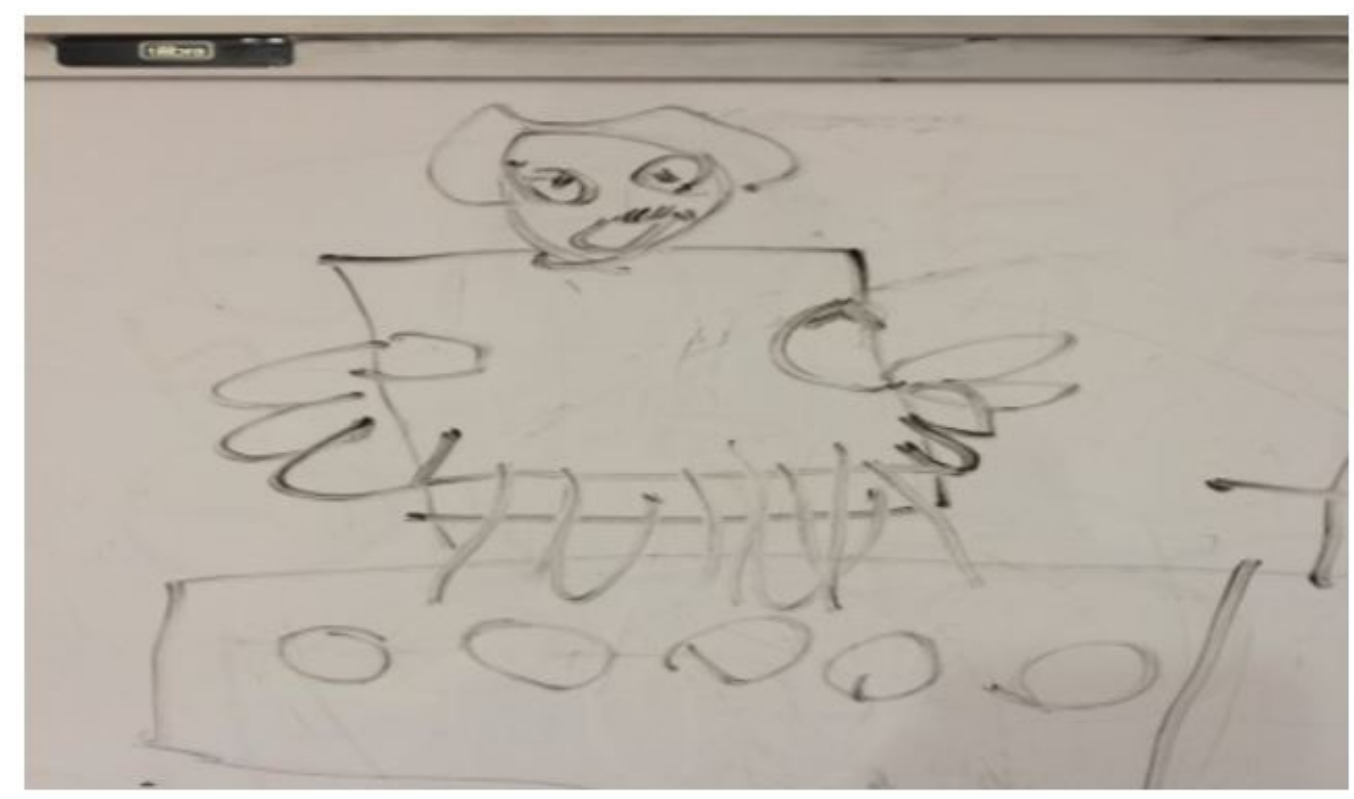

Figura 1. Desenho feito por um dos pacientes do Centro. Fonte: Acervo Pessoal. 


\section{ijhe}

Ela responde sinalizando com a cabeça positivamente.

"- E a gente come?"

Ela responde fazendo gestos, levando a mão à boca.

"Vamos levar a Barbie ao salão?"

Pego a escova de cabelo entrego a ela, que então começa a pentear a boneca.

Instrumentos metodológicos feitos de E.V.A eram utilizados para ensinar às crianças as cores (Figura 3), os números (Figura 4), gênero e expressões faciais (Figura 5). Esta metodologia torna-se muito eficaz, visto que elementos visuais, como figuras e desenhos proporcionam melhor aprendizado às pessoas autistas.

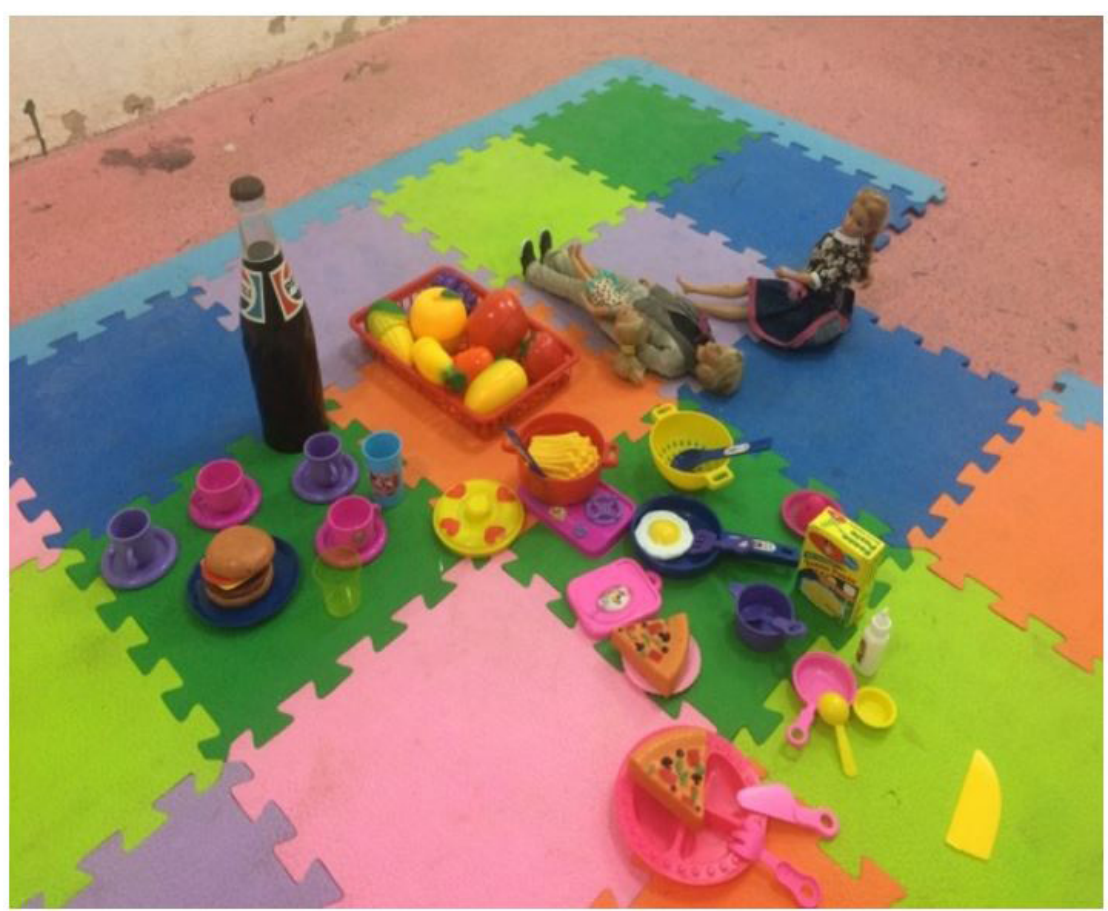

Figura 2. Atividade "FAZ DE CONTA". Fonte: Acervo Pessoal.

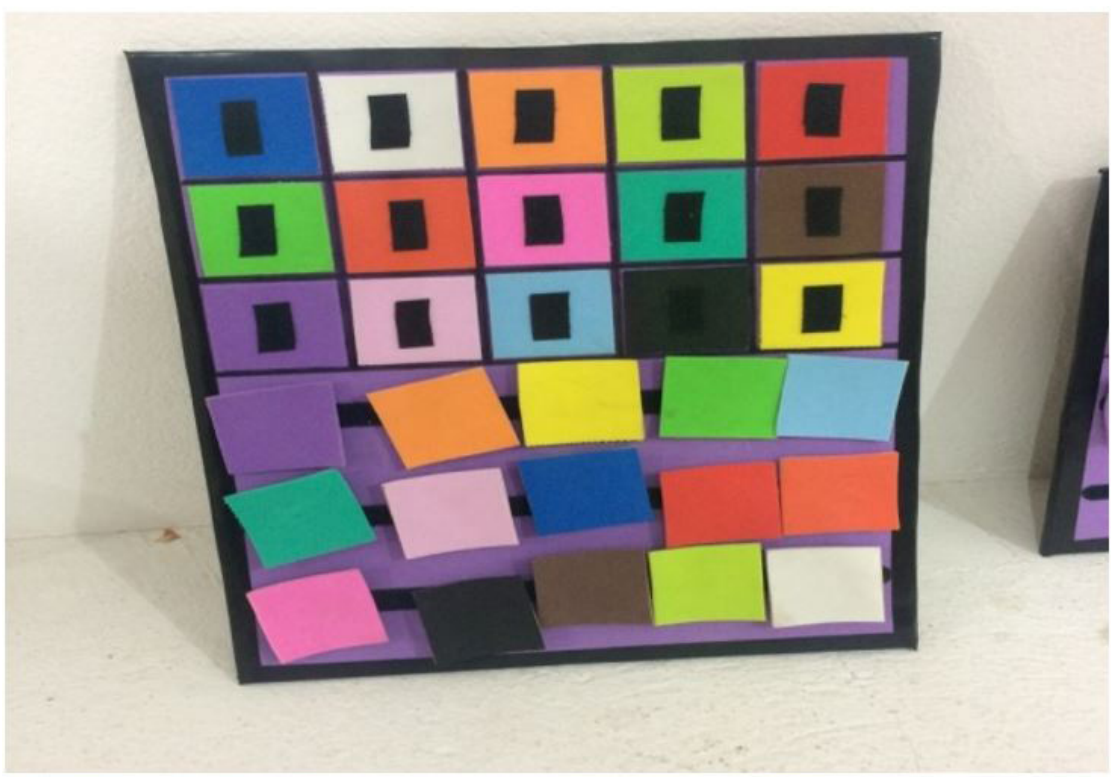

Figura 3. Recurso feito de E.V.A para ensinar as cores. Fonte: Acervo Pessoal. 


\section{iighe}

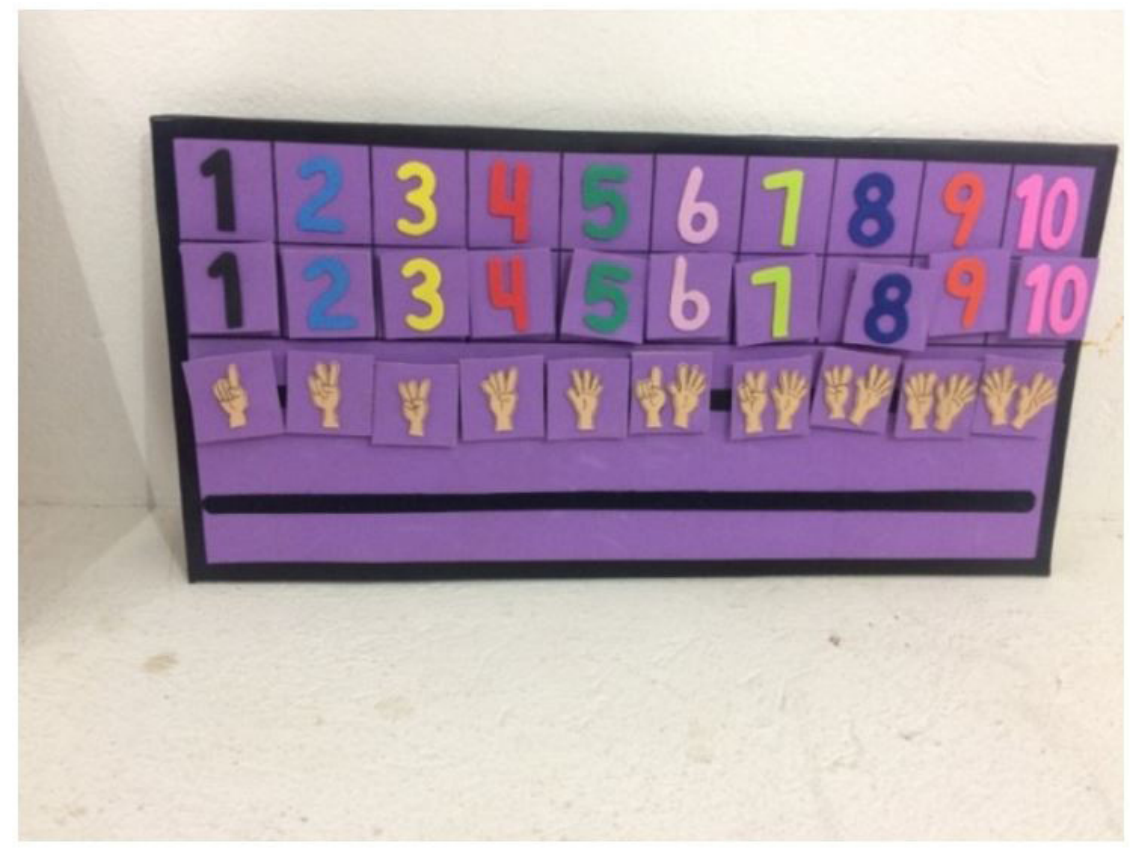

Figura 4. Recurso feito de E.V.A para ensinar os números. Fonte: Acervo Pessoal.

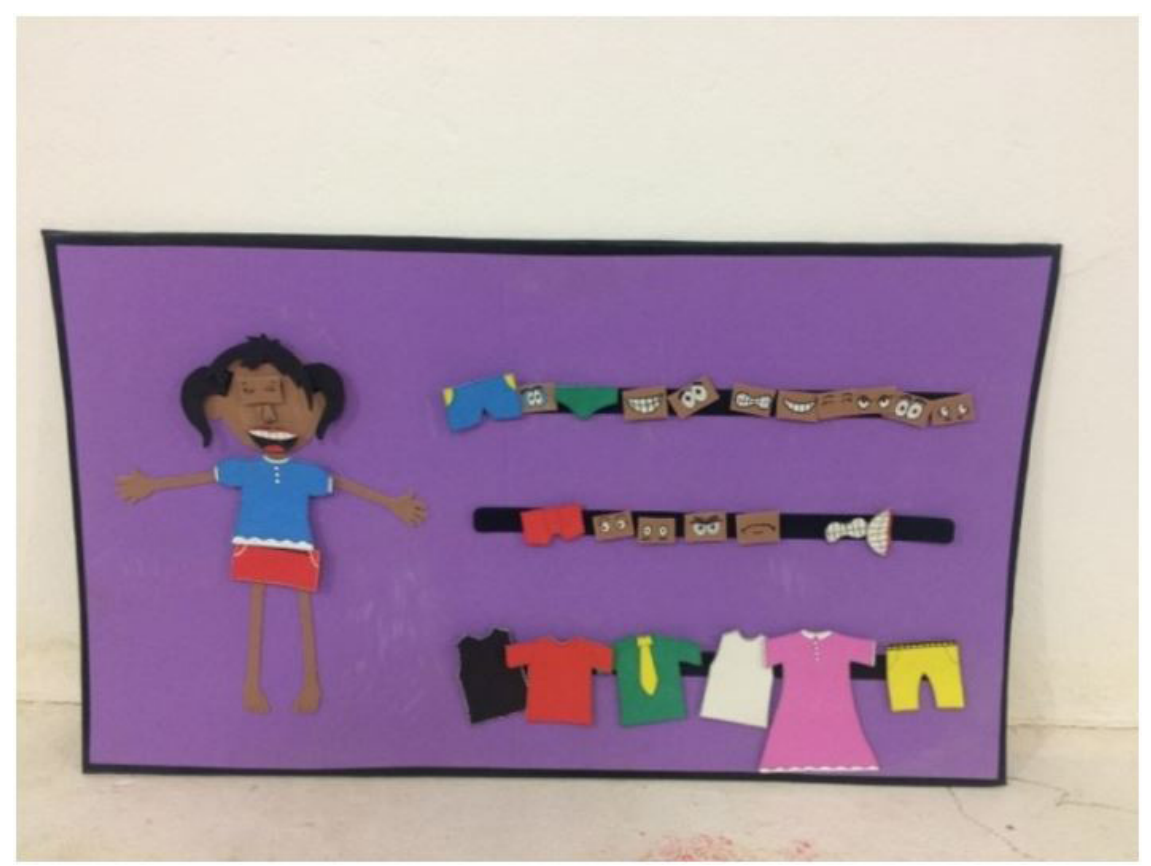

Figura 5. Recurso feito de E.V.A para ensinar gênero e expressões faciais. Fonte: Acervo Pessoal.

Devido ao fato de pessoas com autismo possuírem sensibilidade a determinadas texturas, como o áspero, por exemplo, foi elaborado este recurso, denominado "Árvore dos sentidos" (Figura 6), onde proporcionávamos as crianças o toque de diversos tipos de texturas, objetivando diminuir o desconforto causado por alguma delas.

As pessoas com autismo possuem o desenvolvimento motor global e fino comprometido, basicamente os reflexos, o equilíbrio e a marcha. Tendo como tendo como objetivo estimular a melhora destes aspectos e aumento de sua confiança, lançamos mão do uso da cama elástica e da bola de borracha. 


\section{ijhe}

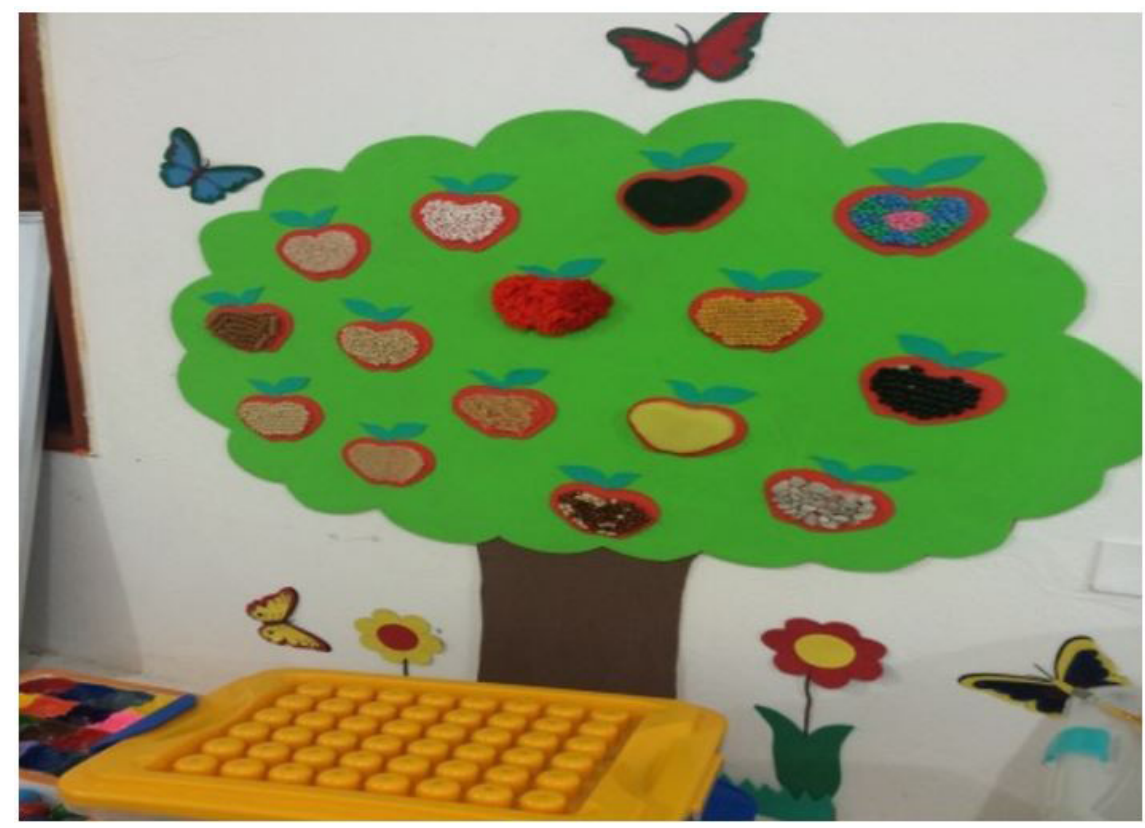

Figura 6. A árvore dos sentidos. Fonte: Acervo Pessoal.

\section{Considerações finais}

Apresentamos algumas orientações, metodologias e recursos utilizados durante as oficinas no CAPSi, baseando nossos trabalhos na Teoria Sócio Histórica de Vygotsky. Ressaltam-se alguns casos de evolução em relação à interação, aspecto mais comprometido em pessoas autistas, enfatizando a importância da intervenção para o desenvolvimento pleno destas pessoas desde a infância.

A monitoria sendo uma atividade de apoio aos processos de ensino-aprendizagem e preparação para formação futura do docente permite adquirir experiências e saberes, tanto nos aspectos dos saberes populares, quanto nos saberes técnico-científicos.

As demandas do mercado impõem ao docente a preocupação com as características dos alunos, principalmente em relação aos alunos com necessidades educacionais especiais, visto que, não somos realmente preparados para atendê-los durante a graduação. A importância desta experiência não pode ser mensurada, mas o aprendizado e a convivência com estas metodologias serão registros importantes no quotidiano da prática profissional, nutrindo o mesmo com um olhar mais aguçado em torno das pessoas com necessidades especiais.

A monitoria busca mais aprimoramento acadêmico diante da oportunidade de vivências, atividades teóricas e práticas. Espera-se que esse estudo contribua para a sensibilização em torno da educação inclusiva, para a compreensão e importância destes tipos de vivências, além de proporcionar uma reflexão acerca dos estigmas e estereótipos em relação às pessoas com deficiência, valorizando suas potencialidades dentro e fora do ambiente escolar com vista a promover a emancipação humana, que é o verdadeiro exercício da cidadania.

Acreditamos ser necessário estender o estudo a outras realidades. São necessários, ainda, estudos que permitam o acompanhamento de experiências similares a fim de identificar outras dificuldades e/ou facilidades neste processo.

\section{Referências}

1. Brasil. Lei no 13.146, de 6 de julho de 2015. Institui a Lei Brasileira de Inclusão da Pessoa com Deficiência (Estatuto da Pessoa com Deficiência). Diário Oficial da União, Brasília, DF, 6 jul. 2015.

2. Farias IM, Maranhão RVA, Cunha ACB. Interação professor-aluno com autismo no contexto da educação inclusiva: análise do padrão de mediação do professor com base na teoria da Experiência de Aprendizagem Mediada. Rev Bras Educ Espec. 2008;14(3):365-84. 
3. Pereira KF, Schmitt BD. Produção de conhecimento sobre autismo na escola: uma revisão sistemática na base Scielo. Cinergis. 2016;17(1):68-73. http://dx.doi.org/10.17058/cinergis.v17i1.7135.

4. Brasil. Ministério da Educação. Portal Brasil. Educação inclusiva. Estatísticas revelam que política adotada pelo governo promove acesso e expansão. Brasília; 2014 [citado em 2016 Abr. 02]. Disponível em: http://portal.mec.gov.br/component/ tags/tag/31872

5. Caminha VL, Huguenin J, Assis LM, Alves PP. Autismo: vivências e caminhos. São Paulo: Blucher, 2016. ePUB.

6. Brasil. Lei $\mathrm{n}^{\circ}$ 12.764, de 27 de dezembro de 2012, que institui a Política Nacional de Proteção dos Direitos da Pessoa com Transtorno do Espectro Autista; e altera o $§ 3^{\circ}$ do art. 98 da Lei n ${ }^{\circ}$ 8.112, de 11 de dezembro de 1990. Diário Oficial da União, Brasília, DF, 27 dez. 2012.

7. Brasil. Ministério da Educação. Secretaria de Educação Especial. Saberes e práticas da inclusão: estratégias para a educação de alunos com necessidades educacionais especiais. Brasília. 2003 [citado em 2016 Maio 02]. Disponível em: http://portal. mec.gov.br/seesp/arquivos/pdf/serie4.pdf.

8. Fernandes NC, Cunha RR, Ferreira AB, et al. Monitoria acadêmica e o cuidado da pessoa com estomia: relato de experiência. Revista Min Enferm. 2015;19(2):238-41.

9. Orrú SE. A Formação de Professores e a Educação de Autistas. OEI-Revista Iberoamericana de Educación. 2003:1-15 [citado em 2016 Maio 03]. Disponível em: http://atividadeparaeducacaoespecial.com/wp-content/uploads/2014/07/ FORMA $\%$ C3\%87\%C3\%83O-DE-PROFESSORES-PARA-A-EDUCA $\%$ C3\%87\%C3\%83O-DE-AUTISTAS.pdf

10. Franzoi MAH, Santos JLG, Backes VMS, Ramos FRS. Intervenção musical como estratégia de cuidado de enfermagem a crianças com transtorno do espectro do autismo em um centro de atenção psicossocial. Texto Contexto Enferm. 2016;25(1):1020015. http://dx.doi.org/10.1590/0104-070720160001020015.

11. Vygotsky LS. A formação social da mente: O desenvolvimento dos processos psicológicos superiores. 5. ed. São Paulo: Martins Fontes; 1994.

12. Nunes DRP, Araújo ER. Universitários com Síndrome de Asperger: potencialidades e desafios. Natal: Programa de Pósgraduação em Educação, Universidade Federal do Rio Grande do Norte; 2011.

13. Sanini C, Bosa CA. Mediação, autismo e educação infantil: Práticas para engajar a criança em atividades. In: Anais do V Congresso Brasileiro de Comunicação Ativa; 2012. Porto Alegre: Universidade Federal do Rio Grande do Sul; 2012 [citado em 2016 Maio 04]. Disponível em: http://www.ufrgs.br/teias/isaac/VCBCAA/pdf_resumo/116539_1.pdf

14. Santos SB. Perturbações do Espectro do Autismo: estratégias inclusivas na sala regular do $1^{\circ} \mathrm{CEB}$ [dissertação]. Lisboa: Escola Superior de Educação Almeida Garrett; 2012.

\section{Contribuição dos autores}

Todos os autores, Paula Raimunda Araújo Teixeira, Maicon de Araujo Nogueira, Antônia Margareth Moita Sá, Lúcia Menezes de Medeiros e Ivonete Vieira Pereira Peixoto tiveram participação suficiente no trabalho para assumir a responsabilidade pelo conteúdo integral, concepção e planejamento do projeto de pesquisa; obtenção ou análise e interpretação dos dados, redação e revisão crítica do texto/conteúdo. 